\title{
Competição e conflito em redes de economia solidária: análise do projeto de implantação da Central de Comercialização de Resíduos Sólidos de Porto Alegre (Brasil)
}

\section{Competition and conflict in an economic "solidary" network: an analysis of the reasons for the failure of a Collective Solid Waste Commercialization Center in Porto Alegre, Brazil.}

\author{
Rosinha Machado Carrion ${ }^{1}$
}

\begin{abstract}
Resumo
Construído a partir dos resultados da pesquisa que investigou inovações em empreendimentos de economia solidária, este artigo analisa, à luz da teoria dos campos (BOURDIEU, 1989), as razões do fracasso do projeto que visava implantar uma central coletiva para a comercialização de resíduos sólidos (Cicrs), na Região Metropolitana de Porto Alegre (RMPOA). Entre os fatores que teriam contribuído para o insucesso da referida proposta - que contava com uma extensa lista de apoiadores -, destaca-se a disputa entre lideranças das duas principais correntes políticas representativas dos trabalhadores do setor de reciclagem A principal contribuição do artigo reside em problematizar o conflito de interesses e as disputas de poder, dois temas "tabus" nos estudos sobre redes de economia solidária.
\end{abstract}

Palavras-chave: rede de economia solidária; Central de Comercialização de Resíduos sólidos; competição; conflito.

\begin{abstract}
The article uses Bourdieu's Field Theory to analyze the findings of an exploratory-descriptive study, carried out in Solidary Economy "enterprises", in order to uncover the reasons that led to the failure of a local Government project to establish a Collective Solid Waste Commercialization Center in Porto Alegre (Brazil), that had been requested by workers within the Solidary Economic Sector. Among the factors that contributed to the failure of this project, one is particularly noteworthy: strong competition between members of the solidary recycling network.
\end{abstract}

Keywords: "solidary" economic network; Collective Solid Waste Commercialization Center; competition; conflict.

\section{Introdução}

Este artigo se integra à linha de estudos sobre gestão do desenvolvimento e analisa a dinâmica das relações em redes de economia solidária. Construído com base nas conclusões de pesquisa de âmbito internacional, cujo objetivo foi investigar inovações em curso em empreendimentos de economia solidária, articula elementos de natureza sócio-político-econômica, para analisar as razões do insucesso do projeto de implantação de uma central para a comercialização coletiva de resíduos sólidos (Cicrs), na Região Metropolitana de Porto Alegre (RMPOA).

A proposta, situada na linha "historicista" (AROCENA, 1998), apresentava características inovadoras. De um lado, contemplava interesses do movimento social de economia solidária; de outro (ao implantar a referida central), o poder público municipal de Porto Alegre estaria, simultaneamente, não apenas atendendo a uma

\footnotetext{
1 Doutora em Administração pela Universidade Federal do Rio Grande do Sul/UFRGS.Professora da Escola de Administração da Universidade Federal do Rio Grande do Sul, onde coordena o Núcleo Transdisciplinar de Pesquisa e Estudos sobre o Terceiro Setor/Nipets/PPGA/UFRGS. Foi Diretora-Presidente da Escola Superior de Administração Pública do Estado do Rio Grande do Sul/ESAPERGS. É pesquisadora do Conselho Nacional de Desenvolvimento Científico e Tecnológico (CNPQ). Endereço: Rua Washington Luiz, 855 - Porto Alegre/Rio Grande do Sul - Brasil - CEP.: 90.010-460. E-mail: carrion@ea.ufrgs.br.
}

Artigo submetido em maio e aceito em novembro de 2008. 
antiga reivindicação dos catadores (os trabalhadores responsáveis pela triagem dos resíduos), mas também melhorando as condições ambientais da cidade.

Ao atentarmos para o cenário, um significativo conjunto de fatores apontava para o sucesso da iniciativa:

1. a implantação da central atenderia uma antiga reivindicação dos catadores;

2. o projeto, já aprovado pelo poder público municipal (PMPA, DMLU, SMIC, SECR, 2003), representava o resultado de um longo processo de negociação entre os órgãos públicos responsáveis pelo tratamento de resíduos sólidos em Porto Alegre e a Federação das Associações de Reciclagem do Rio Grande do Sul (FARRGS), a entidade sindical representativa dos catadores;

3. o espaço físico para a implantação da central, que fora cedido pela ONG Moradia e Cidadania, da Caixa Econômica Federal (CEF), estava localizado em local, logística e ambientalmente adequados para os fins a que se destinava;

4. a Prefeitura Municipal já disponibilizara os recursos financeiros para o custeio das adaptações necessárias nesse imóvel;

5. o Banco Nacional de Desenvolvimento Econômico e Social (BNDES) já havia liberado os recursos para o financiamento das atividades de formação e capacitação dos catadores;

6. a ONG Centro de Aperfeiçoamento Multiprofissional (Camp), identificada com o movimento local de economia solidária, já dera início às atividades de capacitação gerencial e de formação dos catadores para os valores solidários, por meio de convênio firmado com a Prefeitura de Porto Alegre; e

7. a Agência de Desenvolvimento Solidário (ADS), filiada à Central Única dos Trabalhadores (CUT) e, politicamente, identificada com o movimento nacional de economia solidária e ao movimento nacional dos catadores, vinha participando das reuniões que o Departamento Municipal de Limpeza Urbana (DMLU) - o organismo que coordenava o Sistema Integrado de Resíduos Sólidos (GIRS), em Porto Alegre - realizava, semanalmente, com o conjunto de agentes envolvidos na implantação da referida central.

Observado pelo ângulo da teoria das redes, o projeto reunia um conjunto de condições para ter sucesso, pois:

- contava com uma significativa e qualificada rede de apoiadores, cada um com atribuições claramente definidas;

- fora construído com a participação de todos os interessados;

- os recursos materiais e financeiros necessários estavam assegurados; e

- a força de trabalho estava recebendo capacitação técnica para as novas atribuições associadas à implantação da central, bem como, sendo iniciada nos valores da proposta solidária.

Por outro lado, a instalação da central traria também vantagens para todos. Para os catadores, o ganho, individualmente auferido, aumentaria em conseqüência da comercialização coletiva de resíduos. A direção da FARRGS sairia fortalecida, na medida em que a central atenderia uma antiga reivindicação da categoria de trabalhadores que representava. Os recursos financeiros que o Camp estava recebendo, em virtude do convênio com a prefeitura, chegavam num momento muito oportuno, dada a situação de aperto financeiro que aquela ONG vinha enfrentando, em virtude da retração de seus tradicionais financiadores estrangeiros. A Caixa Econômica Federal, por sua vez, ao apoiar o projeto da central, por intermédio de sua entidade social - a ONG Moradia e Cidadania - afirmava, perante a sociedade, seu compromisso com a responsabilidade social corporativa. Ao financiar a formação dos catadores, o Banco Nacional de Desenvolvimento Econômico e Social - que tantas vezes fora acusado de beneficiar grandes investidores privados - demonstrava sensibilidade com os problemas das camadas menos favorecidas da sociedade. A cidade vivia o período pré-eleições municipais, e a inauguração da central representava para o Partido dos Trabalhadores, no comando da 
prefeitura de Porto Alegre, a oportunidade para reafirmar o compromisso político-partidário com os segmentos menos favorecidos da população.

A pergunta que fica, então, é: por que fracassou uma proposta técnica e ambientalmente correta, sustentada por valores - aos quais Mance (2003) atribui o sucesso das redes solidárias - e que contava com uma extensa e qualificada rede de apoiadores?

Fenômenos sociais são fenômenos complexos; portanto, tentar explicitá-los por uma única via seria um equívoco. Isso significa dizer que temos consciência de que qualquer tentativa de interpretação será sempre parcial, dado corresponder a uma, entre diferentes escolhas teóricas e, metodologicamente, possíveis. Todavia, ainda que limitantes, escolhas se impõem como condição para a problematização do objeto de estudo.

A construção do modelo de análise do fracasso do projeto de implantação da central, apóia-se, assim, na sociologia compreensiva de Bourdieu $(1980,1989)$ e, em particular, nas noções de campos e habitus. A de habitus - que se refere ao funcionamento sistemático do corpo socializado - embasou a identificação do "lado ativo do conhecimento prático" dos agentes em diferentes posições no campo. Quanto à noção de campo, foi incorporada para que fossem apreendidas "propriedades do campo". Isto é, para caracterizar as formas de agir, comuns a conjuntos de atores que ocupam posições similares no interior da rede de reciclagem

\section{O estudo das redes à luz das pesquisas sobre gestão}

Ainda que abundantes na literatura de administração, os estudos sobre redes tendem a recair, como sinaliza Benassi (1995), nas estruturas de funcionamento, negligenciando-se com isso a dinâmica do processo. Por vezes, são os fatores que motivam as empresas a adotarem essa forma organizacional (DOSI e al. 1991) que ganham destaque; ora são as implicações das redes para a geração de emprego (CARLEIAL, 2001). Noutras ocasiões, a ênfase recai sobre o desenho das redes (MONIZ; KÓVACS, 2001) e no seu potencial de contribuição para processos inovadores (NIELSEN, 2001),bem como na construção de tipologias (COOKE et al, 1997). Também não se pode esquecer dos estudos de caráter profético, como o realizado por Castels:

Nosso estudo sobre as estruturas sociais emergentes, nos domínios da atividade e da experiência humana, leva a uma conclusão abrangente: como tendência histórica, as funções e os processos dominantes na era da informação estão cada vez mais organizados em torno de redes. Redes constituem a nova morfologia social da nossa sociedade. (CASTELS, 1999, p.497)

A tendência a privilegiar as estruturas em detrimento das relações, sinalizada por Gobibi (2005), evidencia-se também no campo dos estudos de gestão social, conforme se pode observar nos estudos de Guarnieri (2004), ao analisar a contribuição das redes para o desenvolvimento sustentável; de Martinho (2005), ao apontar a contribuição das redes para a Economia Solidária; e de Zapata e Parente (2002), ao analisar os fatores a serem considerados para a formação de parcerias bem-sucedidas.

Por outro lado, quando tais estudos tratam de temas relacionais como a solidariedade, por exemplo, ainda é bastante comum, tratando-se de análises de teóricos da economia solidária, que o lugar do pesquisador seja ocupado pelo do ativista de um movimento social. Isto é, que o pesquisador confunda seu desejo com a realidade dos fatos, como acontece com Mance (2003, p.178), ao afirmar que:

a colaboração solidária vai além da dimensão econômica [...] fortalece a amizade entre as pessoas. Suprimindo toda forma de discriminação e preconceito, e promovendo a diversidade cultural e a criatividade humana.

Situação essa denunciada por Pauli (2006, p.69), ao analisar o livro A revolução das redes, do mesmo Mance (2001):

temos [que] embora as redes de economia solidária articulem fluxos de poder, elas não o problematizam quanto à existência de conflitos, resistências, interesses e outros atributos das relações 
do poder no exercício da ação coletiva [...] [A] perspectiva teórica dessas redes extrai elementos da teoria dos sistemas, que por sua vez procura compreender o movimento e a organização da realidade a partir de sua funcionalidade, pelos princípios de auto-referência, complexidade, sistema $e$ autopoiese.

O comportamento do agente, como aponta Mangematin (1999), é o resultado de um processo no qual o sujeito avalia, com base em suas experiências passadas, as perdas e os ganhos associados a cada alternativa de ação.

A disposição para cooperar, por sua vez:

depende da satisfação experimentada pelos parceiros com relação ao resultado de sua cooperação e como resultado das relações passadas, de comportamentos e de interdependências. [Na] realidade, a percepção da confiabilidade pode se reportar tanto a um indivíduo, como a um parceiro institucional. (KOENIG, 1999, p.143-144)'

A cooperação não se dá, assim, ao acaso. Ela resulta - parafraseando Bourdieu (1989) - de "disposições apreendidas do corpo socializado". Além disso, pode ser entendida como uma tendência, que, para se manifestar, exige que efetivamente haja confiança. (BOURQUE, 1999). Isso significa também dizer que o agente se disporá a cooperar se vivências anteriores forem reativadas de modo positivo pelos atributos da situação que vivencia no presente.

Para entender-se o modo como o passado se reativa no presente, recorre-se a Bourdieu.

\section{A contribuição da sociologia refletiva de Plerre Bourdieu à compreensão das relações em rede}

Ao analisar a ação social em seu livro $O$ poder simbólico, Bourdieu alerta os pesquisadores para os riscos de interpretar o "real" a partir das relações sociais imediatamente visíveis, informando serem as "relações objetivas, entre as posições ocupadas por esses agentes, que determinam a forma de tais interações" (BOURDIEU, 1989, p.66).

Este artigo considera a premissa de "que como condição para o evitamento da análise dissocializada e supradeterminada, e para pôr em evidência as capacidades criativas, ativas e inventivas dos atores", é preciso sair da filosofia da consciência e do determinismo estruturalista, "reintroduzindo, desse modo, uma relação de cumplicidade ontológica com o mundo" (Ibidem p.62) / (BOURDIEU, op. cit., p.62). Nesse sentido, tomou por base as noções de habitus e de campo, concebidas por Bourdieu (1980, 1984, 1989), para construir um modelo de análise que explicasse o fracasso do projeto de construção da central de matérias-primas na Região Metropolitana de Porto Alegre.

O habitus, conforme Bourdieu, remete a:

sistemas de disposições duradouras e transponíveis, estruturas propensas a serem estruturantes. Isto é, funcionam como princípios geradores e organizadores de práticas e representações adaptáveis a seus fins, sem a necessidade de uma visão consciente destes, nem o domínio absoluto das operações necessárias para atendê-los. Trata-se de estruturas reguladas e regulares, que de modo algum são um produto da obediência a regras; sendo tudo isso, coletivamente orquestradas, sem resultarem da ação organizadora de um chefe de orquestra [...] Produto da história, os habitus produzem práticas individuais e coletivas, portando história, conforme os roteiros engendrados pela história. Eles asseguram a presença ativa das experiências passadas, que depositadas em cada organismo na forma de esquemas de percepção, de pensamento e de ação, tendem - mais do que todas as regras formais $e$ todas as normas explícitas - a garantir a conformidade com as práticas e sua constância através dos tempos. (BOURDIEU, 1980, p.88-89).

Para não ser taxado de estruturalista como os althusserianos, ele acrescenta: 
como todos os conceitos dispositionnels, o conceito de habitus - que o conjunto dos usos históricos predispõe a designar como um sistema de disposições adquiridas, permanentes e produtoras -, vale mais, talvez, e antes de tudo, pelos falsos problemas e as falsas soluções que elimina, as questões que permite melhor formular ou responder, as dificuldades propriamente científicas que faz aflorar. (BOURDIEU, 1980, p.89)

Como, então, interpretar a ação social considerando-se que os habitus, ou seja, as "estruturas cristalizadas" de percepção, construídas com base em experiências anteriores, ainda que modelem, não determinam o comportamento humano? A explicação é dada por Bourdieu, ao analisar as razões que levam uma determinada manifestação artística a assumir a supremacia sobre as outras, em dado momento histórico. O fato - como explica - não se deve, necessariamente, a um maior valor intrínseco da obra, mas à possibilidade que detêm, aqueles que com ela se identificam, de lançarem mão do prestígio social, associado à posição que ocupam no meio (leia-se "campo") literário e/ou artístico, para o convencimento dos demais do "valor" que desejam que seja atribuído à obra. Essa capacidade de mobilização da conduta, decorrente de capitais acumulados, é denominada por Bourdieu de "poder simbólico".

Ao refletir sobre os ativos dos quais se valem os agentes para defenderem seus interesses, Bourdieu (1980) assinala quatro tipos de "capitais", que tanto podem existir em "estado objetivado", como em "estado incorporado". Como exemplo de capital objetivado, ele cita o patrimônio e o conjunto de bens materiais. Já os demais, seriam da ordem do estado incorporado: o capital social, que remete à rede de relações pessoais à disposição do agente; o capital cultural, representado pelo conjunto de atributos ou qualificações intelectuais; e o capital ou poder simbólico, que corresponde à soma dos demais.

Síntese da combinação dos demais capitais - com a particularidade de que aqueles que o detêm podem mobilizar os demais tipos de capital em proveito próprio -, o capital simbólico tem o poder de "construir realidades" (BOURDIEU, 1989), sendo tanto mais efetivo quanto mais o dominado não perceba estar a serviço da vontade de outrem. Isto é, quanto mais ele acreditar que age por livre e espontânea vontade, mais a submissão assume o caráter de uma imposição "consentida".

O poder de dominação, como no caso das ideologias, faz-se tanto mais forte quanto mais o discurso de quem detém o capital simbólico for aceito como sinônimo de verdade inquestionável.

Para Bourdieu, o Estado, em função de ter o controle sobre os aparelhos ideológicos, como a educação e a Justiça, representa a instância máxima desse tipo de poder.

Outra noção fundamental à sociologia da ação de Bourdieu (1980) é a de campo. Este é entendido como um espaço imaginário - como "palco", nos dizeres de Shakeaspeare e Goffman - no qual atores dotados de diferentes capitais disputam, entre si, posições de poder e prestígio. Vencem aqueles que dispuserem dos habitus ou disposições, socialmente, mais valorizadas.

Assim, enquanto o habitus informa a tendência para agir do corpo socializado - ou seja, o lado "potencialmente ativo do conhecimento prático" - as "propriedades do campo" referem-se ao padrão de relações objetivas, isto é, ao modo como os agentes utilizam seus capitais para fazerem o jogo pender a seu favor.

O agir ou a "conduta" do ator sobre a cena corresponde, assim, ao "híbrido" resultante, de um lado, da tendência incorporada para agir e, de outro, da capacidade do agente de ajustar-se às propriedades do campo, o que pode ser traduzido por "aprender a jogar o jogo". Desse modo, a ação social pode ser pensada como síntese, simultaneamente, do passado, do aprendido e do presente, que é onde se dá a atualização do habitus e, portanto, onde existe espaço para a inovação.

O sentido da ação não está, pois, no que é dito. O sujeito não fala, ele é "falado" (LACAN, 1985), e o discurso não é mais do que "linguagem de madeira" (PÊCHEUX, 1988); de tal modo que, para apreender o sentido do que é dito, é preciso recorrer à análise da formação discursiva de que fala o sujeito (FOUCAULT, 1969). Dessa forma, a resposta para a pergunta "Por que o projeto da central de matérias-primas fracassou? não teria de ser 
buscada no discurso, nem em palavras como "solidariedade" (empregada como aposto explicativo para descrever a rede de "apoiadores" do setor de triagem") ou "autogestão" (apontada como símbolo da harmonia nas relações de trabalho no interior das associações). A resposta estaria na reconstrução histórica das propriedades do campo e no modo como a situação presente reativa experiências anteriores.

\section{0 método e as técnicas de pesquisa}

Os dados já estavam disponíveis. Eles haviam sido coletados pelo método de observação participante, entendido como o método em que o observador participa da vida das pessoas em estudo, tanto abertamente no papel de pesquisador, como assumindo papéis e observando fatos que acontecem; escutando o que é dito e questionando as pessoas (TRAUTH; O'CONNOR, 2000).

Durante dois anos, interagiu-se com o conjunto dos atores do setor de triagem no processo de implantação e de desenvolvimento da tecnologia social de residência solidária (CARRION; VALENTIM; HELLWIG: 2006). Foram percorridas as 13 associações de triagem em operação na RMPOA, visitadas as instalações, observadas as linhas de produção e mantidas conversas com os catadores. Por vezes, em companhia de técnicos do Camp; em outras, de modo independente. Além disso, participou-se de várias das reuniões semanais realizadas na sede do DMLU, com a presença de técnicos do poder público, de coordenadores de associações de triagem e de representantes das ONGs envolvidas no projeto. Também houve participação em fóruns de economia solidária, em encontros de formação dos catadores, em reuniões de mobilização das associações para o projeto de implantação da central (promovidas pelo Camp), bem como do encontro estadual (igualmente promovido pelo Camp) voltado para o planejamento estratégico do setor de triagem do Rio Grande do Sul. Nesta ocasião, o representante de uma das associações de triagem, politicamente próximo da direção da FARRGS, questionou a presença de técnicos da ADS na reunião, pois o identificava como alinhado ao Movimento Nacional dos Catadores de Materiais Recicláveis (MNCMR). Dispunha-se, assim, no diário de campo, de um farto registro das situações observadas.

Havia também a transcrição das fitas com entrevistas realizadas com:

- os dirigentes das 13 associações de triagem vinculadas ao Sistema de Gerenciamento Integrado de Resíduos Sólidos (GIRS), da Prefeitura Municipal de Porto Alegre;

- com a presidente da FAARGS;

- com a liderança do MNCMR em Porto Alegre;

- com técnicos do Camp e da ADS;

- com o diretor do DMLU;

- com o coordenador do Programa de Economia Solidária, da Secretaria Municipal de Indústria e Comércio de Porto Alegre, então responsável pela política pública de economia solidária para o setor de reciclo;

- com a coordenadora da Incubadora Tecnológica de Economia Solidária, criada por deliberação popular por meio do orçamento participativo;

- com o coordenador da ONG Moradia e Cidadania da CEF;

- com o irmão responsável pela coordenação do trabalho dos padres maristas de apoio financeiro às associações de triagem; e

- com catadores.

A esse imenso conjunto de dados que deu origem a uma série de artigos, relatórios, vídeos, seminários, capítulos de livros e a um livro, com o relato do processo de desenvolvimento da tecnologia social de residência solidária (CARRION; VALENTIM; HELLWIG, 2006) somavam-se, ainda, informações recolhidas de fontes secundárias, como jornais, folders, material de divulgação de feiras, fóruns...; ou seja, já se tinha 
material. Faltava apenas construir o modelo de análise, para o que se apoiou em Bourdieu, e definir o método para a análise dos dados.

Quanto ao método de análise dos dados, criou-se um híbrido, apoiado, de um lado, nas categorias habitus, capital social, capital econômico e capital simbólico e, de outro, no método (ORLANDI, 2005) de análise do discurso. Esse método "não se constitui simplesmente em uma aparelhagem técnica, mas igualmente em um modo de intervenção política" (COURTINE, 2006, p.15), partindo do entendimento de que o discurso corresponde ao lugar, ao momento em que "se pode observar a relação entre a língua e a ideologia" (ORLANDI, 2005, p.17).

\section{Propriedades do "campo", interesses em conflito e disputa por posições}

No início da década de 1990, as áreas utilizadas pela Prefeitura Municipal de Porto Alegre para depositar o lixo urbano estavam esgotadas, enquanto os movimentos ambientalistas que já pressionavam pela adoção de soluções limpas que não comprometessem o meio ambiente já ganhavam espaço na mídia. $\mathrm{O}$ caminho encontrado pelo poder público seria a implantação do Sistema Integrado de Gerenciamento de Resíduos Sólidos (GIRS), cuja coordenação ficaria sob a responsabilidade do Departamento Municipal de Limpeza Urbana (DMLU), o órgão já então responsável pela coleta seletiva do lixo urbano.

Para dar conta de sua nova atribuição, o DMLU organizou os catadores autônomos, que recolhiam por conta própria o lixo da cidade, em associações de triagem. A decisão pela organização dos catadores, sob a forma jurídica "associação" resultou do desejo de evitar a formação de vínculo trabalhista; ou seja, de impedir que, no futuro, os catadores pudessem entrar com reclamatórias trabalhistas contra a Prefeitura. $\mathrm{O}$ argumento político, utilizado para justificar o ato, seria, no entanto, o de que o poder público estaria assegurando condições dignas de trabalho aos catadores.

Na sequiência, a Central Única dos Trabalhadores (CUT) se envolveu no processo, começando a difundir a proposta da economia solidária para organizar o trabalho no interior das associações.

O poder público, também identificado com o Partido dos Trabalhadores, não interferiu no projeto da CUT. A princípio, havia cooperação entre os dois grupos, ainda que, em determinados momentos, tenham ocorrido conflitos, como quando a CUT se uniu aos catadores para pressionar o DMLU pela melhoria das condições materiais das associações.

Em 2004, ao iniciar a pesquisa de campo - que se estendeu até 2006 - já havia na RMPOA, 12 associações de triagem, às quais se somaria mais uma em 2005. Elas gozavam de boa visibilidade social e contavam com uma extensa rede de "apoiadores". Isto é, de agentes que aportavam algum tipo de contribuição; alguns, de modo mais permanente - como os irmãos maristas, ONGS como a Caritas, a Avesol, a ADS e o Camp, além de instâncias do setor público -, e outros, como empresas, universidades e profissionais autônomos, que aportavam contribuições pontuais e também de caráter voluntário.

Entretanto, na medida em que o movimento social dos catadores e o movimento social de economia solidária ganhavam visibilidade e passavam a ocupar "posições" no espaço público político, iniciavam também as disputas pelo poder. Lutas estas que, na Região Metropolitana de Porto Alegre, vão produzir uma cisão entre as lideranças do setor de reciclagem e dar origem a duas facções políticas em acirrada disputa pelo controle da Federação das Associações de Reciclagem do Rio Grande do Sul (FARRGS), ou seja, do sindicato do setor.

De um lado, estava a facção que vencera as eleições para a presidência da FAARGS e, de outro, a derrotada. A primeira tinha por base de sustentação política as lideranças da maioria das associações de reciclagem; do movimento local de Economia Solidária, e do PT Amplo. Ou seja, da corrente do Partido dos Trabalhadores, que estava no poder na Prefeitura Municipal de Porto Alegre. Já a segunda, que era liderada pela representação local do Movimento Nacional dos Catadores (MNC), e reunia as lideranças do setor de reciclagem que tinham perdido a disputa para a presidência da FARRGS, contava com o apoio político do movimento nacional de 
economia solidária e de lideranças do Partido dos Trabalhadores identificadas com a tendência "democracia radical", então, com forte presença em cargos de decisão no Poder Executivo, em Brasília, a capital do país.

Cada um das facções lançava mão de seus "capitais" para fazer valer seu discurso político. O grupo no comando da FARRGS apontava como indicador de sua legitimidade para falar em nome do coletivo de trabalhadores, o fato de ter sido eleito através de eleições democraticamente realizadas. Já, a facção representativa do MNC, para desqualificá-lo, o acusava de ter negociado com o DMLU, um acordo relativo à implantação da Central de Comercialização que continha cláusulas nocivas aos interesses dos catadores, no que não deixava de ter razão.

Pressionado por grupos econômicos, que forçavam para entrar no rico negócio de reciclagem, o poder público municipal - dando nítidos sinais de flexibilização da ideologia petista - colocara cláusulas no projeto que não apenas transferiam para as associações custos como a água, a energia e a compra de equipamentos de proteção, como criavam obrigações sociais a serem pagas pelos catadores. Esse conjunto de fatores caracterizava, nitidamente, uma situação de terceirização do serviço de triagem.

Por outro lado, para manter o controle da situação, o poder público, como estratégia para "comprar" o silêncio do MNC, dispusera-se a ceder parte das instalações do prédio onde iria operar a central de comercialização de resíduos para carroceiros. Isto é, para os trabalhadores politicamente alinhados ao MNC, que, por disporem de carroças para recolher os resíduos sólidos na cidade, não dependiam do fornecimento de matéria-prima pelo DMLU.

Por outro lado, apesar das concessões que fazia às lideranças do MNC, o projeto da central - sacramentado em acordo firmado entre o DMLU e a FARRGS, em 2004 - estabelecia que a comissão de gerência da central fosse constituída por representantes do DMLU, da Secretaria Municipal de Indústria e Comércio, da própria FARRGS, da ONG Moradia e Cidadania e das associações que aceitassem fornecer seu produto à central. Portanto, não previa a representação do MNC, representação esta que o MNC ambicionava - apesar de acusar o projeto de ser perverso para os trabalhadores do setor - por saber que a central atendia a um anseio antigo da categoria e reconhecer que o fato de não estar participando, afastava-o ainda mais da possibilidade de voltar a assumir o controle da FARRGS.

A diretoria da FARRGS, por sua vez, apesar de desgostosa com o DMLU - o qual ao ceder espaço aos carroceiros autônomos no prédio destinado à central, reduzira o número de associações que teriam seu material comercializado na central de modo coletivo - para defender-se das acusações do MNC, curvava-se ao jogo político dos governantes, mesmo que com isso comprometesse os interesses de seus representados. Todavia, se aparentemente ganha em capital social, perde em poder simbólico.

Fornecedor quase exclusivo da matéria-prima (os resíduos urbanos) para as associações, e representante do Estado no campo, o DMLU associava ao monopólio do poder econômico, o poder simbólico. Além disso, na posição de "fiel" da balança - em parte, por retribuição à fidelidade da direção da FARRGS; em parte, para anular o poder de fogo do MNC - reconhecia a FARRGS como a legítima "interlocutora dos catadores organizados" (PMPA, DMLU, SMIC; SECR, 2003, p.7). O Movimento Nacional dos Catadores busca flexibilizar essa situação, denegrindo a imagem da direção da FARRGS perante o movimento nacional de economia solidária, processo esse no qual obtém sucesso.

A disputa e os ataques mútuos assumiam, assim, progressivamente, um caráter pessoal. Para consolidar sua posição no campo, as lideranças locais do Movimento Nacional dos Catadores - aproveitando-se da disputa em Porto Alegre entre facções do PT pelo controle simbólico da economia solidária - buscaram (e conseguiram) apoio financeiro do governo federal para dar andamento a seu projeto de implantação de uma central de comercialização de resíduos própria; ou seja, de uma segunda central, que iria operar paralelamente à que estava sendo implantada pela municipalidade de Porto Alegre.

Paralelamente, em reunião realizada em Brasília, em meados de 2004, para o lançamento da Rede Ecosol de Economia Solidária, o maior desafeto político da presidência da FARRGS (mas identificado com o MNC) foi 
indicado para representar a Rede Nacional de Economia Solidária no Rio Grande do Sul. Uma vez eleito, ele vai utilizar o poder simbólico decorrente de um cargo de nomeação federal para desqualificar o presidente da federação. Em consequiência desse golpe simbólico, pouco a pouco, os coordenadores das associações de triagem que, tradicionalmente, tinham apoiado a presidente da FARRGS, vão se distanciando desta.

Com a perda da base política, esvaiu-se o pouco capital simbólico que a FARRGS ainda reunia e, consequientemente, ela deixou de ter interesse para os governantes, até ter sua posição - e o capital social a ela associado - esvaziados. Já enfraquecido, em parte, também pelo deslocamento da atenção dos gestores públicos para suas respectivas campanhas eleitorais, o processo de implantação da central caminhou para o esgotamento.

Era, igualmente, possível observar que, quanto mais desprovidos de capital social, quanto mais frágeis suas respectivas posições no campo, mais os coordenadores das associações tendiam a se envolver em pactos, os quais eram desfeitos com a mesma rapidez com que eram tecidos, do que resultava um clima de desconfiança no campo, que tornava inviável a cooperação.

Já a ADS e o Camp - que dispunham de capital cultural semelhante, mas estavam em constante disputa pelos recursos públicos destinados à formação/capacitação -, para contrabalançarem sua dependência do Estado acabavam se envolvendo em pequenas intrigas fomentadas pelas facções em disputa no campo. A expectativa era a de, apoiando uma facção ou outra, instituírem-se perante os gestores públicos como parceiros preferenciais, dado que estariam mais aptas a influenciar o processo de preferências político-partidárias dos trabalhadores do setor de reciclagem. Por outro lado, o jogo duplo dos gestores públicos, tentando contemplar interesses díspares, contribuía para acirrar ainda mais a disputa entre as associações, para inviabilizar a cooperação que seria tão importante, tão fundamental e tão necessária para a consolidação do setor e para a sobrevivência dos trabalhadores que têm nessa atividade seu ganha-pão.

Há também que se considerar como uma das razões do fracasso do processo de implantação da central, o fato de que as reuniões técnicas promovidas pelo DMLU não contemplaram o espírito do que seja esfera pública, que é o "espaço social de interação entre os diferentes grupos e atores sociais que se fundamentam nas associações e nas organizações autônomas da sociedade civil mediadoras entre cidadãos dotados de direitos". Cabe ainda observar que essas reuniões tinham como principal função legitimar decisões já tomadas, caracterizando-se, assim, aquilo que Becker (2000) denomina de "não participação", manipulação ou, participação "instrumental".

\section{Considerações finais}

A partir do modelo de análise baseado na teoria dos campos, de Bourdieu, verificamos que as intensas e históricas disputas no campo do reciclo - cristalizadas em habitus de desconfiança e de invalidação, como estratégia para conquistar o poder simbólico -, quando reativadas pelo viés clientelista ${ }^{2}$ da cultura local, inviabilizariam a cooperação entre as lideranças da "rede" de reciclagem responsáveis por defender os interesses dos trabalhadores do setor.

Paralelamente, foi possível constatar, por meio da situação analisada, que as redes de "economia solidária", assim como os demais tipos de redes, são suscetíveis a conflitos de poder que, se não forem adequadamente tratados, podem inviabilizar a cooperação. É o que teria ocorrido no caso do projeto de implantação da Central de Comercialização Coletiva de Resíduos Sólidos, em Porto Alegre.

Não é demais relembrar, ainda, o risco de buscar-se o sentido dos fatos nas palavras, sobretudo, em um momento como o atual, em que se vive uma crise discursiva, como sinaliza Dagnino (2005). O que significa dizer que palavras como solidariedade, participação e democracia perdem seu sentido original, podendo estar a serviço de projetos políticos muito diferentes e, por vezes, até mesmo antagônicos. 


\section{Referênclas}

AROCENA, José. Los paradigmas del desarrollo y lo local. Cuadernos del Claeh, Montevideo, v.41, p.5-21, 1998)

BENASSI, Michel. Governance factors in a network process approach. Scandinavium Journal of Management, v.11, n.3. p.103-117, 1995.

BOURDIEU, Pierre. Le sens pratique. Paris: Les Éditions du Minuit, 1980.

Questions de sociologie. Paris: Les Éditions du Minuit, 1984.

O poder simbólico. Lisboa: Difel, 1989.

BOUROUE, Reynaud. Confiance et négociation. In: THUDEROZ, Christian; MANGEMATIN, Vincent; HARRISSON, Denis. La confiance: approches économiques et sociologiques. Quebec. Gaëtan Morin, 1999. p.263-287.

CARLEIAL, Liana. Redes industriais de subcontratação: um enfoque de Sistema Nacional de Inovação. São Paulo: Hucitec, 2001)

; VALENTIM, Igor; HELLWIG, Beatriz (Org.). Residência solidária UFRGS: a vivência de universitários com o desenvolvimento de uma tecnologia social. Porto Alegre: Editora da UFRGS, 2006.

CASTELS, Manuel. A sociedade em rede. São Paulo: Paz e Terra, 1999.

COOKE, P. E et alii. Regional innovation systems: institutional and organizational dimentions. Research Policy, n.26, p.475-491, 1997.

COURTINE, Jean-Jacques. Metamorfoses do discurso político: derivas da fala pública. São Carlos: Claraluz, 2006.

DAGNINO, Evelina. Os movimentos sociais e a emergência de uma nova noção de cidadania. In: DAGNINO, E. (Org). Os anos go: política e sociedade no Brasil. São Paulo: Brasiliense, 1994.

DMLU - Departamento Municipal de Limpeza Urbana. Central de Comercialização de Materiais Recicláveis (CCMR). DMLU, SMIC, FARRGS, associações de recicladores. Porto Alegre, set. 2004. Mimeografado. p.1-17.

Minuta de convênio. Porto Alegre, 16 dez. 2003. p.1-6. Mimeografado.

DOSI, Giovanni et al (Org.). Technology and enterprise in a historical perspective. Oxford: Oxford University Press, 1991)

FEDOZZI Luciano. Orçamento participativo: reflexões sobre a experiência de Porto Alegre. Porto Alegre: Editorial Tomo, 1997.

FOUCAULT, Michel. L'archéologie du savoir. Paris: Gallimard, 1969.

GOBIBI, Beatriz et al. Politizando o conceito de redes organizacionais: uma reflexão teórica da governança como jogo de poder. Cadernos Ebape.BR, Rio de Janeiro, v.III, n.1, mar. 2005. Disponível em: <www.ebape.fgv.br/cadernosebape>.

GUARNIERI, Maria Cristina de Lourdes. Governança de (em) redes sociais - uma contradição? Disponível em: <http://www.Rits.org.br>. Acesso em: 2 dez. 2004.

KOENIG, Christian. Confiance et contrat dans les aliances interentreprises. In: THUDEROZ. Christian; MANGEMATIN, Vincent; HARRISSON, Denis. La confiance: approches économiques et sociologiques. Quebec: Gaëtan Morin, 1999. p.126-145.

LACAN, O seminário - livro 2: o eu na teoria de Freud e na técnica da psicanálise. Rio de Janeiro: Jorge Zahar, 1985.

MANCE, Euclides André. A revolução das redes. Petrópolis: Vozes, 2001.

Como organizar redes solidárias. Rio de Janeiro: DP\&A/Fase, 2003.

MANGEMATIN, Vincent. La confiance: un mode de coordination dont l'utilisation dépend de ses conditions de production. In: THUDEROZ, Christian; MANGEMATIN, Vincent; HARRISSON, Denis. La confiance: approches économiques et sociologiques. Quebec: Gaëtan Morin, 1999. p.31-54.

MARTINHO, Cássio. Redes e desenvolvimento local. Disponível em: <http://www.rebea.org.br/rebea/arquivos/redesdlcassiom.pdf>. Acesso em: 14 set. 2005. 
MONIZ, A.; KOVÁCS, I. Sistemas antropocêntricos de produção: uma alternativa para a Europa? In: KOVÁCS, I.; CASTILLO, J. J. (Org.). Novos modelos de produção: trabalho e pessoas. Oeiras: Celta, 2001. p.65-80.

NIELSEN, Bo Bernhard. Synergies in strategic alliances: motivation and outcomes of complementary and synergistic knowledge networks. Copenhagen Business School, 2001. Mimeografado.

ORLANDI, Eni P. Análise de discurso: princípios e procedimentos. Campinas: Pontes, 2005.

PAULI, Jandir. O poder nas redes de economia solidária. Dissertação (Mestrado em Sociologia) - Universidade Federal do Rio Grande do Sul, Porto Alegre, 2006.

PÊCHEUX, M. Semântica e discurso. Campinas: Pontes, 1988.

PMPA, DMLU, SMIC, SECR (Secretaria Extraordinária de Captação de Recursos). Projeto Integrado de Qualificação, Sistema de Coleta Seletiva e Triagem de Resíduos Sólidos do Município de Porto Alegre. Central de Comercialização de Materiais Recicláveis. Porto Alegre: Prefeitura Municipal, jul. 2003. p.1-17. Mimeografado.

THUDEROZ. Christian; MANGEMATIN, Vincent; HARRISSON, Denis. La confiance: approches économiques et sociologiques. Quebec: Gaëtan Morin, 1999.

TRAUTH, Eileen M.; O'CONNOR, Barbara. A study of the interaction between information technology and society: an illustration of combined qualitative research methods. Disponivel em: <http://www.cba.neu.edu/ etrauth/works/ifip5.txt >. Acesso em: 10 maio 2000.

ZAPATA, Tânia; PARENTE, Silvana. O desenvolvimento institucional e a construção de parcerias para o desenvolvimento local. [S.I.: s.n.], maio 2002. p.22. Mimeografado.

\footnotetext{
${ }^{1}$ Tradução do autor.

${ }^{2}$ O clientelismo é entendido como "rede de fidelidades pessoais que passa, quer pelo uso pessoal, por parte da classe política, dos recursos estatais, quer partindo destes, em termos mais imediatos, pela apropriação dos recursos autônomos" (FEDDOZI, 1997 apud MATROPA, 1994).
} 